\title{
Prospective Comparative Observational Study of Safety and Efficacy of Topical Ozone Gas Therapy in Healing of Diabetic Foot Ulcers versus Only Conventional Wound Management
}

\author{
Suchin Dhamnaskar, MS ${ }^{1}$ Nishant Gobbur, MS ${ }^{1} \quad$ Mandar Koranne, MBBS, MS ${ }^{1}$ Dhaval Vasa, MS ${ }^{1}$ \\ ${ }^{1}$ Department of Surgery, Seth G.S. Medical College and K.E.M. \\ Hospital, Mumbai, Maharashtra, India \\ Surg J (NY) 2021;7:e226-e236.

\begin{abstract}
Address for correspondence Suchin Sudhakar Dhamnaskar, MS, Department of General Surgery, Seth G.S. Medical College and K.E.M. Hospital, Parel, Mumbai 400012, Maharashtra, India (e-mail: suchinsd@gmail.com).
\end{abstract}

\begin{abstract}
Keywords

- diabetic foot ulcers

- topical ozone gas therapy

- wound healing
\end{abstract}

The prevalence of diabetic foot ulcers (DFUs) in India is $11.6 \%$. DFU accounts for major cost expenditure, morbidity, and mortality. ${ }^{1}$ Ozone gas has antimicrobial and antioxidant properties. We studied efficacy of topical ozone gas therapy in promoting healing of DFU. This is an observational comparative cohort study, $n=160$, There were two groups of patients namely: those who received Conventional wound management alone $C$ and those who received topical ozone therapy in addition to conventional wound management $\mathrm{O}+\mathrm{C}$ therapy groups (81 each). Study group, i.e., $\mathrm{O}+\mathrm{C}$ received five alternate day sessions of ozone therapy by bagging method for 30 minutes each session. Both groups were observed for 30 days for wound healing parameters like reduction of wound surface area, wound diameter, presence and character of discharge, granulation tissue, healing wound edges, microbial negativity, and requirement of revision (re-debridement and/or amputation) surgery. Mean baseline ulcer surface area is $17.43 \pm 8.6 \mathrm{~cm}^{2}$ for $C$ and $17.87 \pm 9.2 \mathrm{~cm}^{2}$ (range $1-50 \mathrm{~cm}^{2}$ ) in $\mathrm{O}+\mathrm{C}$ group. Percentage change in ulcer surface after 21 days in $\mathrm{O}+\mathrm{C}$ group is $32.37 \%$ compared with $17.15 \%$ in $C$ group, which is statistically significant $(p=0.01)$. Rates of microbial negativity and ulcer healing were significantly faster in ozone group. There was a statistically significant decrease in hospital stay, number of revision surgeries required, and mortality in ozone group. Topical ozone gas was well tolerated. Our study supports the efficacy of ozone therapy in DFU healing and reduction in the chances of infection and revision (re-debridement and/or amputation) surgery. More research is needed for dose, duration, and exposure time standardization.
One in four diabetes mellitus (DM) patients are reported to develop diabetic foot ulcer (DFU). ${ }^{1}$ The prevalence of DFU in India is $11.6 \%$ (95\% CI: 6.4-16.8\%). The above data shows that DFU is a very common, complicated, and costly problem that draws researchers' interest to find effective means to prevent or treat it and help its better healing. Ozone is a gas made of

received

February 15, 2021

accepted after revision

May 17, 2021
DOI https://doi.org/

$10.1055 / \mathrm{s}-0041-1731447$

ISSN 2378-5128. three atoms of oxygen with a cyclic structure and can be applied to treat many diseases due to its antioxidant and anti-bacterial properties. For instance, it can be used in the treatment of chronic infections caused especially by antibiotic-resistant pathogens. Recently, the beneficial effects have been found of treating a vascular ulcer with ozone. Moreover,

(C) 2021. The Author(s).

This is an open access article published by Thieme under the terms of the Creative Commons Attribution License, permitting unrestricted use, distribution, and reproduction so long as the original work is properly cited. (https://creativecommons.org/licenses/by/4.0/)

Thieme Medical Publishers, Inc., 333 Seventh Avenue, 18th Floor, New York, NY 10001, USA 
ozone administration can induce tolerance of oxidative stress and prevent damage mediated by free radical. ${ }^{2}$

\section{Aims and Objectives}

\section{Aim}

The aim of the study is to assess the efficacy and safety of topical ozone gas therapy for healing of DFUs.

\section{Objectives}

1. Primary objective:

a. To assess the rate of wound healing in diabetic ulcers.

b. To assess the adverse effects of ozone gas therapy.

2. Secondary objective:

a. To assess the rate of achieving local microbial negativity of wound swabs.

b. To assess the reduction in hospital stay.

c. To assess the rate of formation of healthy granulation tissue.

\section{Material and Methods}

Study design: Prospective comparative cohort observational study.

Study site: Study conducted in tertiary care teaching hospital at developing country.

Study duration: Until the estimated sample size is achieved (81 in each arm).

\section{Inclusion Criteria}

1. All the patients, men or women, with either type- 1 or type-2 DM with a Wagner classification stages 2, 3 or post debridement stage 4 without venous insufficiency or lymphatic obstruction and without spreading cellulitis.

2. Age above 18 years.

\section{Exclusion Criteria}

Wound size of $>50 \mathrm{~cm}^{2}$, gangrenous foot ulcers, active osteomyelitis, history of hypo or hyperthyroidism, hemoglobin A1c (HbA1c) $>10 \%$, ankle-brachial index $<0.8$, hemoglobin level $<8 \mathrm{~g} \%$, serum creatinine level $>2.5 \mathrm{mg} / \mathrm{dL}$ or patient on dialysis, serum albumin level $<2 \mathrm{~g} / \mathrm{dL}$, liver function tests (alanine transaminases, aspartate transaminases) elevated to more than three times the upper normal limit, patients with collagen vascular diseases, patients on steroid therapy, immunosuppressed host, known cancer patient, pregnant females, and post-partum females.

\section{Withdrawal Criteria}

The criteria include patients withdrawing consent for further participation in due course of study at any point of time due any of the adverse effects like pungent smell of ozone gas, etc.

\section{Sample Size Calculation}

$$
\begin{aligned}
& N=\left(Z \alpha_{/ 2}+Z \beta\right)^{2} /(p 1-p 2)^{2} \times P \times(1-P) \\
& \quad N=\text { size per group; } \\
& \quad p 1=\% \text { of ulcers healed in Ozone plus C Group } 24 \%^{3}
\end{aligned}
$$

$p 2=\%$ of ulcers healed in C Group $12 \%^{3}$

$P=$ pooled prevalence $p 1+p 2 / 2=24+12 / 2=18 p=18$

$Z \alpha / 2=Z 0.1 / 2=Z 0.05=1.96-$ From $Z$ table at type I error of $10 \%$

$Z \beta=Z 0.20=0.842$-at $80 \%$ power

Sample size 81 patients in each group.

\section{Procedure}

Study was conducted after institutional ethical approval. All eligible patients were enrolled in the study after informed consent. Treatment arm allocation was done as per treating surgeons' preference and since it was an observational study, investigators had no control over it. All the patients of DFU received conventional wound treatment which consisted of thorough surgical wound debridement followed by daily wound cleaning with desloughing (EUSOL) and antiseptic solution like povidone iodine and application of sterile bandage dressing. Surgical debridement is repeated as and when needed. Once wound turns healthy without any visible slough use of desloughing and irritant antiseptic agent was discontinued and wounds were dressed with emollient agents like paraffin tulle to avoid overgrowth of granulation tissue and sterile bandage. Wound care was performed by surgical resident doctor assisted by the faculty of Department of General Surgery.

Multimodal glycemic control plan with dietary modifications and oral hypoglycemic drugs, and insulin if needed was utilized with aggressive sugar monitoring for all patients.

In addition to above conventional management; study group also received topical ozone gas treatment as follows.

\section{Steps of Ozone Therapy}

Day 1 of ozone therapy: wound is cleansed with saline and wound swab collected for microbial testing. Topical ozone gas therapy was given by bagging technique.

Ozone gas is generated by medical ozone gas generator (-Fig. 1). Pure oxygen is passed through a high voltage gradient in the generator $(5-13 \mathrm{mV})$ which generates ozone according to this chemical reaction: $3 \mathrm{O}_{2}+68.400 \mathrm{cal} \rightarrow 2 \mathrm{O}_{3}{ }^{4}$ Ozone concentration in real time can be determined by a well standardized photometer or iodine titration test. ${ }^{4}$

\section{Bagging Technique}

Wound is cleaned thoroughly with normal saline. A piece of saline soaked sterile gauze is placed over the wound to avoid direct exposure of wound to ozone. A bag is formed as per the size of the wound with use of sterile polythene sheet and adhesive sticking. Bag is placed over the wound and ozone gas outlet pipe is inserted in the bag. Mouth of this bag is sealed by roller bandage to avoid gas leakage ( - Fig. 2). Ozone generator is then connected to oxygen source @1 L/min. Acrid smell is experienced when machine is switched on due to minor leak through bag which is unavoidable. Rate of ozone insufflation is adjusted between 35 and $45 \mu \mathrm{g} / \mathrm{mL}$. Ozone insufflation is given for 5 minutes. Ozone machine is then switched off, outlet pipe taken out from the bag, and its mouth tightened. The inflated bag is kept for 1 hour exposure 


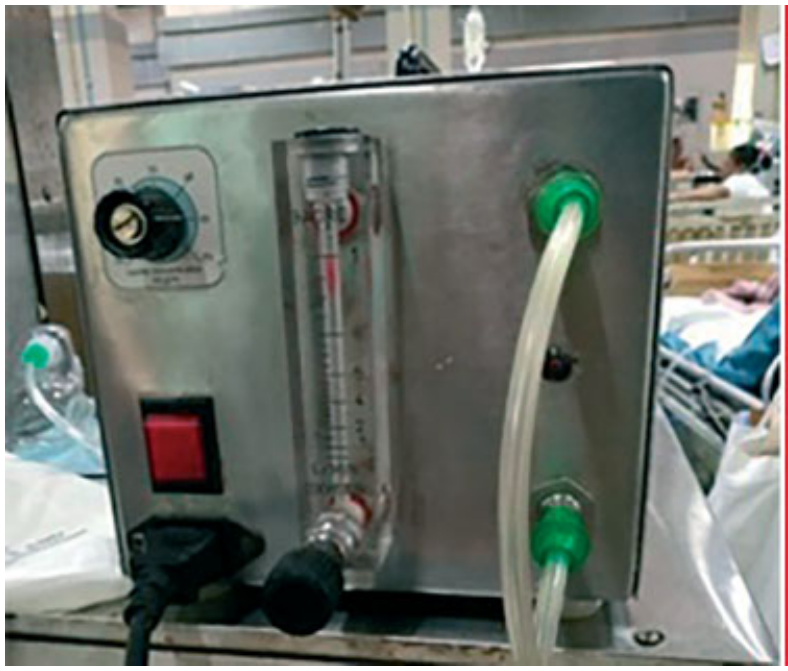

Fig. 1 Ozone generator apparatus.

time for ozone to act on the wound. After 1 hour bag is removed, and sterile dressing done with conventional method.

Five such sessions of ozone therapy are given on alternate day.

Wound swab was taken on day 1 and every fourth day until microbial negativity and then weekly thereafter for all patients.

\section{Clinical Assessment of Wound}

Wound assessment done on day-1, 4, 8, 14, and 21 days for both the groups and each time following outcome parameters were measured.

1. Wound size: Sterile transparent polyethylene dressing placed over the wound which was already covered partially with a sterile gauze in such a way that edges of wound were exposed. A transparent acetate sheet with grid lines tracing is then placed over this sterile polyethylene transparent sheet through which underlying ulcer boundaries could be seen and marked on grid sheet (-Fig. 3). Surface area of big square on grid sheet was $1 \mathrm{~cm}^{2}$ and that of smallest square was $1 \mathrm{~mm}^{2}$.Different

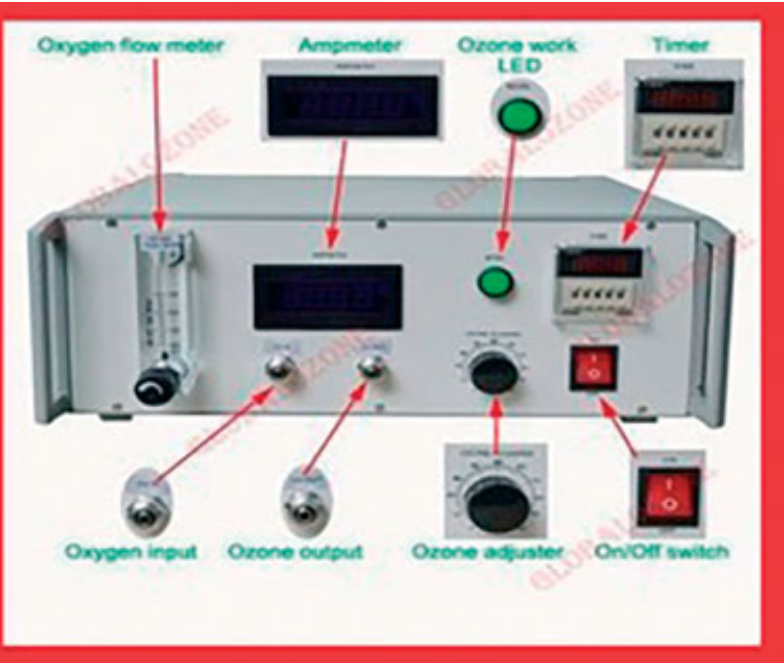

color markers were used for every sequential reading. Surface area of the ulcer is calculated by counting the number of squares contained within the marked boundary of the ulcer tracing. Ulcer diameter was the longest diagonal of that ulcer on the tracing sheet.

2. Character of exudate: : It was recorded by observing the kind of soakage of dressing material. Blood-stained dressing indicates serosanguinous exudate and semipurulent or purulent exudate is seen by just pressing the wound or it's surrounding area.

Grade 1: Serous for watery thin discharge.

Grade 2: Serosanguinous for discharge stained with blood.

Grade 3: Semi-purulent for thin turbid discharge.

Grade 4: Purulent for presence of frank pus in the wound.

3. Granulation tissue: It is newly formed connective tissue and microscopic blood vessels that form on the floor of ulcer during healing process. Characteristics of healthy granulation tissue are light red or dark pink in color, moist, soft to touch, punctate bleeding on touch due to
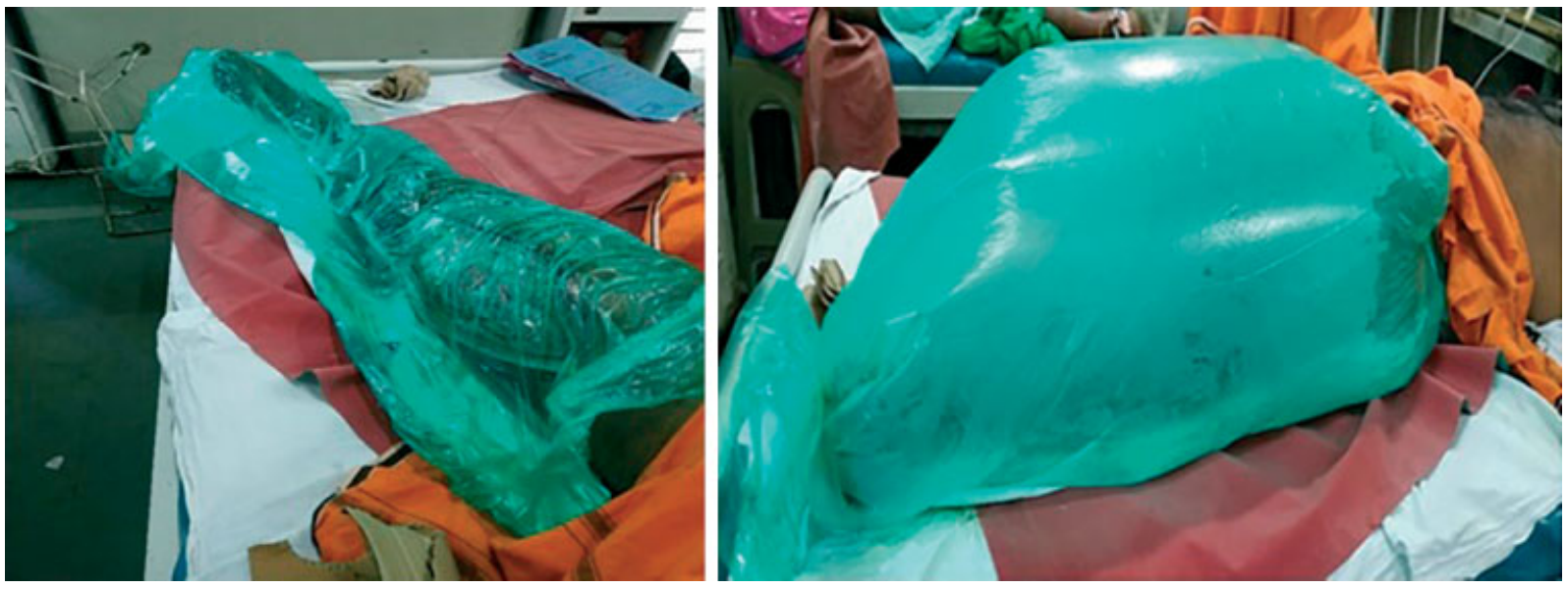

Fig. 2 Bagging technique of ozone gas therapy to lower limb wound. 


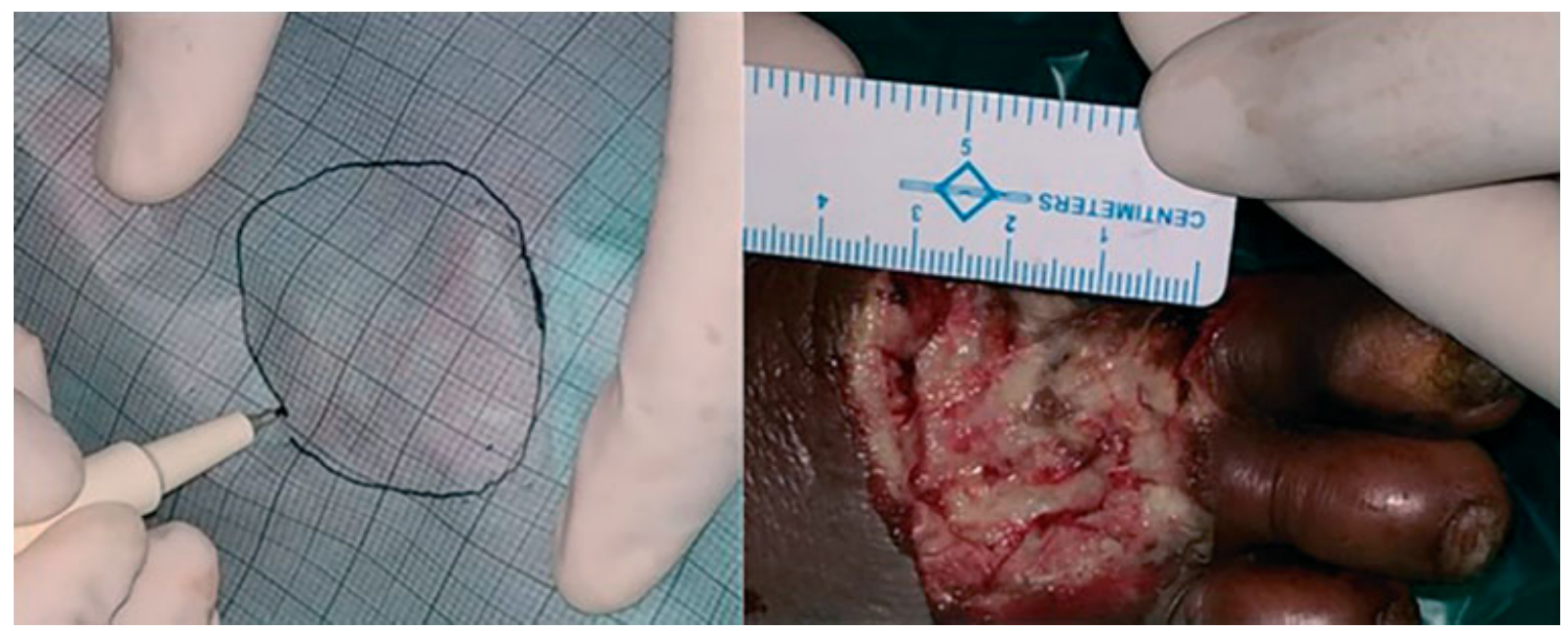

Fig. 3 Ulcer surface area measurement with grid line paper.

newly formed capillary loops, absence of slough, no purulent discharge, and painless. Proportion of ulcer area with healthy granulation tissue corresponds to the extent of healing. It was assessed by visual inspection and graded as below. Granulation tissue consisting of

Score 1: $<25 \%$ of area of the wound

Score 2: 25 to $50 \%$ of area of the wound

Score $3: 50$ to $75 \%$ of area of wound

Score 4: $>75 \%$ of area of wound.

4. Edges of the wound: Sloping edges suggest healing wound. It was assessed as \% of the wound edge that is sloping.

$><25 \%>25-50 \%>50-75 \%>>75 \%$.

Patients were followed up during the hospital stay or within 30 days of admission whichever was later to know if he/she required a revision (re-debridement and amputations) surgery and to know the outcome of the patient.

All the relevant data were entered in predesigned case record form and compared between two groups for each of the outcome parameter to find out statistical significance.

\section{Results}

In our study we had total of 162 patients, 81 each in $C$ and $\mathrm{O}+\mathrm{C}$ therapy group.

1. Wound size: In our study $n=162$, median values of wound surface and maximum wound diameter of $C(n=81)$ and
$\mathrm{O}+\mathrm{C}(n=81)$ are calculated on day $1,4,8,14$, and 21 (-Table 1).

Thus, the change or reduction in mean values of wound surface area and largest wound diameter have significant difference between two groups. If we plot a graph comparing these values of two groups, it shows significant change as shown in - Fig. 4.

On applying, generalized estimated equation for continuous data with interaction term to see the independent association of therapy with ulcer surface area and maximum ulcer diameter, significant interaction term suggest that intervention differences related to ulcer surface area are significantly changing over time with $p$-value $<0.05$. Trajectories of ulcer surface areas (change in ulcer surface area over the period of time) and that of largest ulcer diameter for two interventions were significantly different ( - Table $\mathbf{1}$ and - Fig. 4).

Thus, percent change in ulcer surface area after 21 days was higher $32.37 \%$ in $\mathrm{O}+\mathrm{C}$ group compared with $\mathrm{O}$ alone group. And this change or reduction was statistically significant $(p=0.01)$

Similarly mean reduction in largest ulcer diameter after 21 days was higher for $\mathrm{O}+\mathrm{C}$ group (18.62\%) compared with $\mathrm{C}$ group $(14.02 \%)$ which was statistically significant $(p=0.01)$ (-Table 2)

2. Association of character of wound exudate with $C$ and $O+C$ group: Character of exudate can be purulent,

Table 1 Association of mean decrease in wound surface area and maximum wound diameter with $\mathrm{C}$ and $\mathrm{O}+\mathrm{C}$ therapy

\begin{tabular}{|l|l|l|l|l|}
\hline Days & $\begin{array}{l}\text { Mean surface area } \\
(\mathbf{C}) \text { therapy, } \mathbf{c m}^{2}\end{array}$ & $\begin{array}{l}\text { Mean surface area } \\
(\mathbf{O}+\mathbf{C}) \text { therapy, } \mathbf{c m}^{2}\end{array}$ & $\begin{array}{l}\text { Mean of largest ulcer } \\
\text { diameter }(\mathbf{C}) \text { therapy, } \mathbf{c m}\end{array}$ & $\begin{array}{l}\text { Mean largest ulcer } \\
\text { diameter }(\mathbf{O}+\mathbf{C}) \text { therapy, } \mathbf{c m}\end{array}$ \\
\hline Day 1 & 17.43 & 17.87 & 5.48 & 5.52 \\
\hline Day 4 & 17.06 & 17.16 & 5.37 & 5.39 \\
\hline Day 8 & 16.58 & 16.20 & 5.21 & 5.20 \\
\hline Day 14 & 15.85 & 14.77 & 4.99 & 4.93 \\
\hline Day 21 & 15 & 13.10 & 4.73 & 4.62 \\
\hline
\end{tabular}



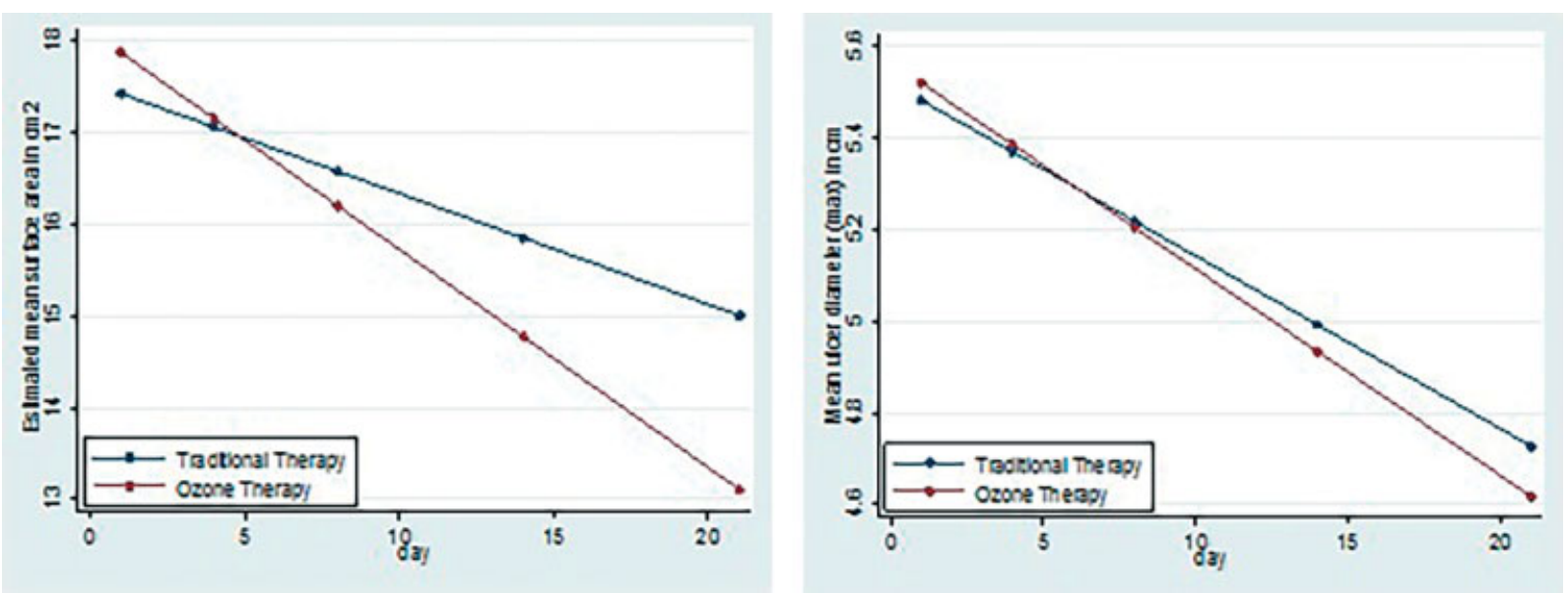

Fig. 4 Association of mean decrease in wound surface area and wound diameter with Conventional $(C)$ and $(O+C)$ therapy.

Table 2 Percent change in wound surface area and maximum wound diameter between day 1 and 21 in $\mathrm{C}$ and $\mathrm{O}+\mathrm{C}$ group

\begin{tabular}{|l|l|l|l|}
\hline & $\mathbf{C}(\boldsymbol{n}=\mathbf{8 1})$ & $\mathbf{O}+\mathbf{C}(\boldsymbol{n}=\mathbf{8 1})$ & Unpaired $t$-test \\
\hline \% Change in surface area, mean (SD) & $17.15(7.48)$ & $32.37(11.49)$ & $\begin{array}{l}t \text {-Value }=-9.92 ; \\
p \text {-Value }=0.01 ;\end{array}$ \\
\hline \% Change in largest diameter, mean (SD) & $14.02(4.68)$ & $18.62(7.53)$ & $\begin{array}{l}t \text {-Value }=-4.66 ; \\
p \text {-Value }=0.01 ;\end{array}$ \\
\hline
\end{tabular}

seropurulent, serosanguinous, or serous and they were respectively given scores as $4,3,2$, and 1 .

When we apply generalized estimated equation for count data with interaction term to see the independent association of therapy with character of exudate, there is significant interaction term which suggests that intervention differences related to character of exudate are significantly changing over time with $p$-value $<0.05$ (-Fig. 5 and - Table 3).

3. Association of rate of formation of healing granulation tissue with $\mathrm{C}$ and $\mathrm{O}+\mathrm{C}$ therapy: To assess the rate of formation of healing granulation tissue scores were given as follow: $<25 \%=1,25-50 \%=2,50-75 \%=3,>75 \%=4$.

When we apply generalized estimated equation for count data with interaction term to see the independent association of therapy with rate of formation of healing granulation tissue, there is nonsignificant interaction term which suggests that intervention differences related to healing granulation tissue are not significantly changing over time with $p$ value $>0.05$. Trajectories of healing granulation tissue (change in healing granulation tissue over the period of time) for two interventions were not significantly different (-Fig. 6 and -Table 4)

(So, we will remove the interaction term from the model and rerun it). At any given time point, healing granulation tissue score is estimated to be $20 \%$ more for patients receiving $\mathrm{O}+\mathrm{C}$ therapy compared with patient receiving $\mathrm{C}$ therapy. This difference was statistically significant.]

4. Association of rate of formation of healing wound edges with $\mathrm{C}$ and $\mathrm{O}+\mathrm{C}$ therapy: To assess the rate of formation of healing wound edges scores were given as follow: $<25 \%=1,25-50 \%=2,50-75 \%=3,>75 \%=4$.

On day 21 , healing wound edges score was estimated to be $27 \%$ more for patients receiving $\mathrm{O}+\mathrm{C}$ therapy compared with

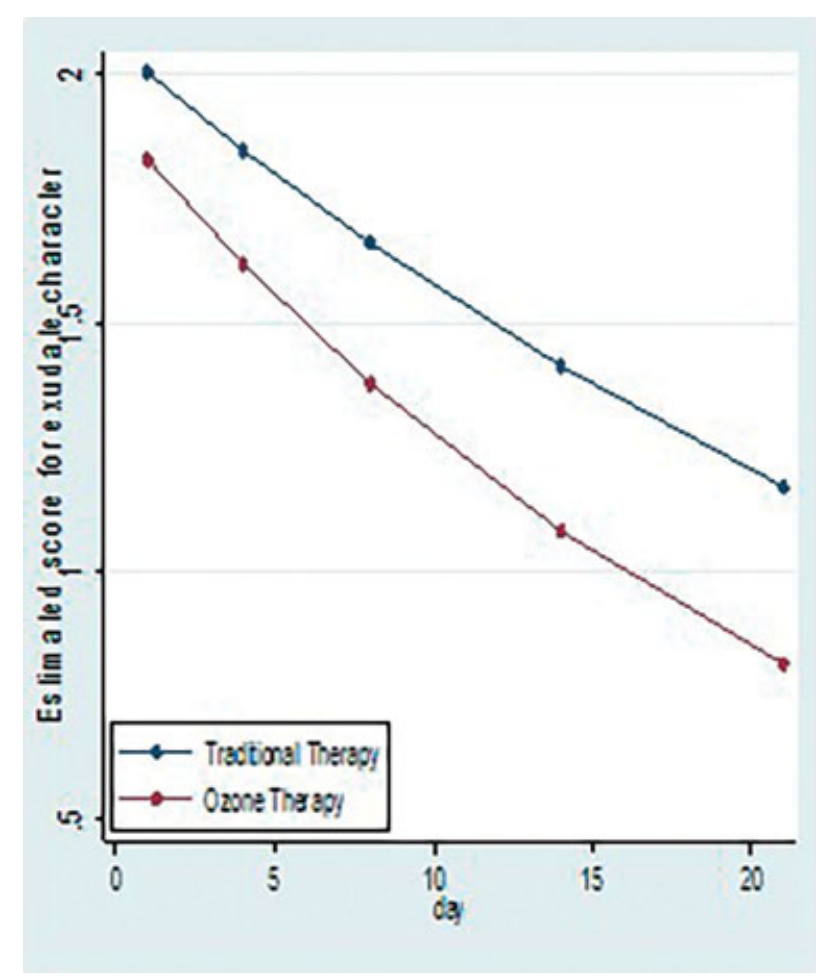

Fig. 5 Comparison of median scores of characters of exudate between two study groups. 
Table 3 Comparison of median scores of characters of exudate between two study groups

\begin{tabular}{|c|c|c|}
\hline \multicolumn{3}{|l|}{ Therapy } \\
\hline $\begin{array}{l}\text { Character of exudate, } \\
\text { median (IQR) }\end{array}$ & C & $\mathrm{O}+\mathrm{C}$ \\
\hline Day 1 & $2(2,2)$ & $2(2,2)$ \\
\hline Day 4 & $2(2,2)$ & $2(1,2)$ \\
\hline Day 8 & $1(1,2)$ & $1(1,1)$ \\
\hline Day 14 & $1(1,1)$ & $1(1,1)$ \\
\hline Day 21 & $1(1,2)$ & $1(1,1)$ \\
\hline
\end{tabular}

patient receiving $C$ treatment. This difference was statistically significant. When we apply generalized estimated equation for count data with interaction term to see the independent association of therapy with healing wound edges, there is significant interaction term, which suggests that intervention differences related to healing wound edges are significantly changing over time with $p$-value $<0.05$ (-Fig. 7 and -Table 5)

5. Adverse effects of ozone: Acrid odor: To assess the noxious nature of odor of ozone gas we used the Likert scale with score of 0 to 5 .

Ozone has acrid odor as an adverse effect but it is not noxious and is well tolerated by patients as shown in $\boldsymbol{- F i g . ~} \mathbf{8}$ and - Table 6 .

6. Association of rate of microbial negativity with $\mathrm{C}$ and $\mathrm{O}+\mathrm{C}$ therapy: Wound culture and antimicrobial sensitivity testing done on day $1,4,8,14$, and 21 for patients of

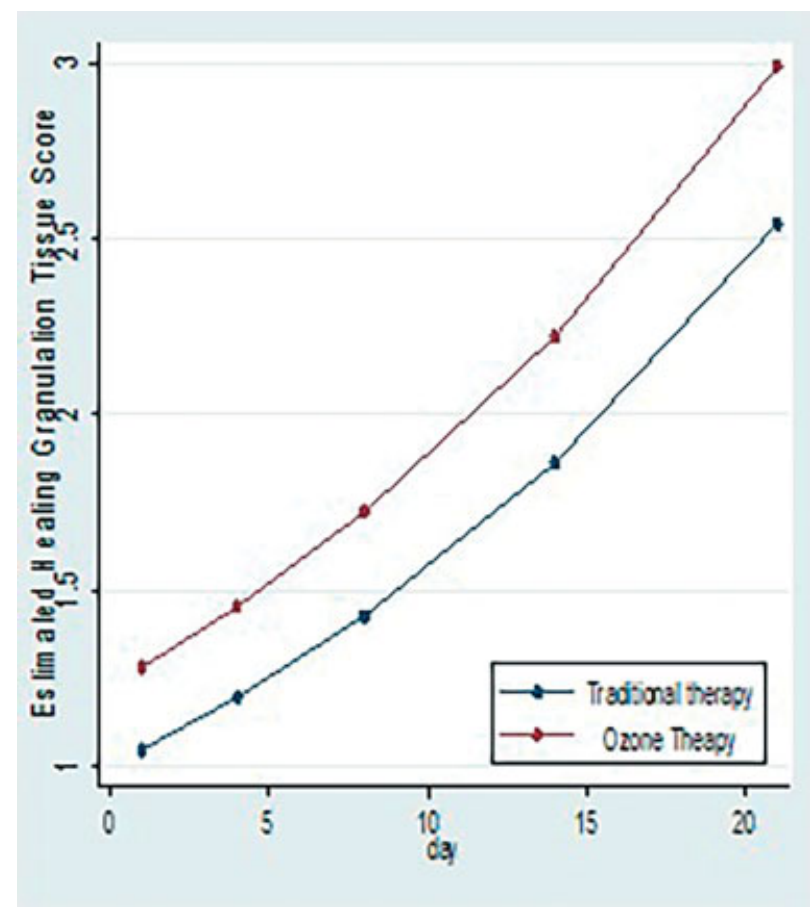

Fig. 6 Comparison of scores of rates of formation of healing granulation tissue in two study groups.
Table 4 Comparison of scores of rates of formation of healing granulation tissue in two study groups

\begin{tabular}{|l|l|l|}
\hline $\begin{array}{l}\text { Healing granulation } \\
\text { tissue, median (IQR) }\end{array}$ & $\mathbf{C}$ & $\mathbf{O}+\mathbf{C}$ \\
\hline Day 1 & $1(1,1)$ & $1(1,1)$ \\
\hline Day 4 & $1(1,1)$ & $1(1,1)$ \\
\hline Day 8 & $2(1,2)$ & $2(2,2)$ \\
\hline Day 14 & $2(2,2)$ & $2(2,2)$ \\
\hline Day 21 & $2(2,3)$ & $3(3,3)$ \\
\hline
\end{tabular}

both the groups. - Fig. 9 shows faster rate of microbial negativity reaching $0 \%$ by day 8 for gram-positive and day 4 for gram-negative organisms in $\mathrm{O}+\mathrm{C}$ group.

To assess the significance statistically we apply generalized estimated equation for binary data with interaction term to see the independent association of therapy with gram-positive organism growth; there is significant interaction term which suggests that intervention differences related to the presence of gram-positive organism growth are significantly changing

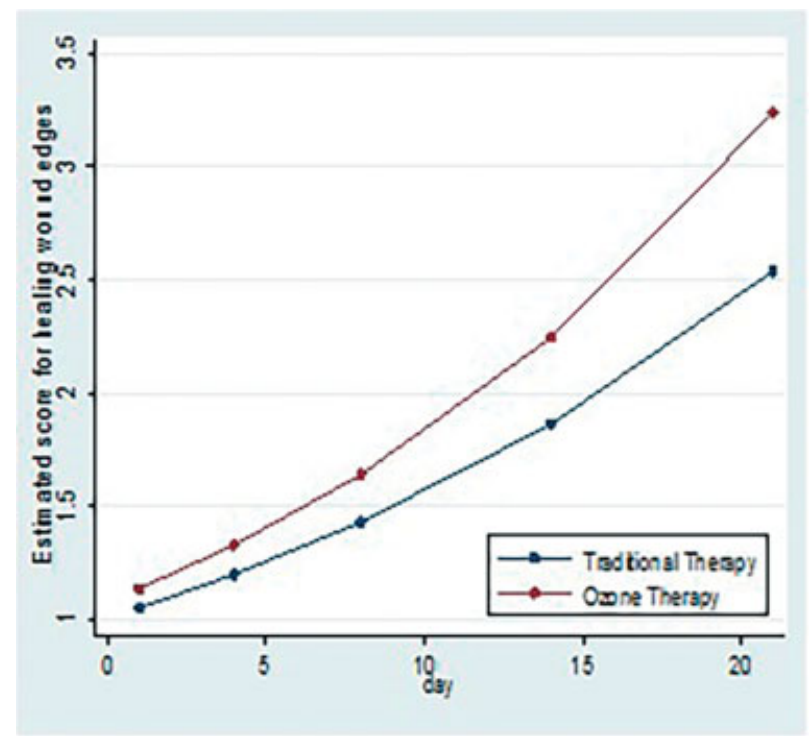

Fig. 7 Comparison of scores of rates of formation of healing wound edges in two study group.

Table 5 Comparison of scores of rates of formation of healing wound edges in two study group

\begin{tabular}{|l|l|l|}
\hline $\begin{array}{l}\text { Healing wound edges, } \\
\text { median (IQR) }\end{array}$ & $\mathbf{C}$ & $\mathbf{O}+\mathbf{C}$ \\
\hline Day 1 & $1(1,1)$ & $1(1,1)$ \\
\hline Day 4 & $1(1,1)$ & $1(1,1)$ \\
\hline Day 8 & $2(1,2)$ & $2(2,2)$ \\
\hline Day 14 & $2(2,2)$ & $3(2,3)$ \\
\hline Day 21 & $2(2,3)$ & $3(3,3)$ \\
\hline
\end{tabular}




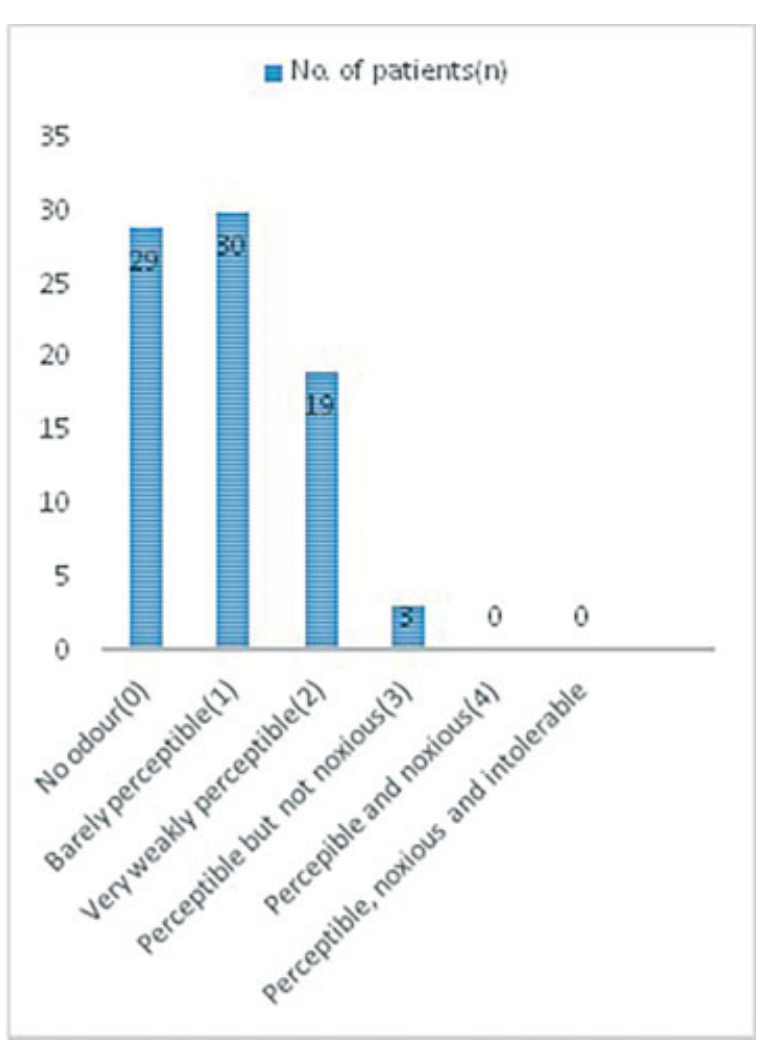

Fig. 8 Likert scale and distribution of patients having different degree of odor intensity.

Table 6 Likert scale and distribution of patients having different degree of odor intensity

\begin{tabular}{|l|l|}
\hline Acrid odor for ozone therapy & Number (\%) \\
\hline 0-No odor & $29(35.8)$ \\
\hline 1-Barely perceptible & $30(37)$ \\
\hline 2-Very weakly perceptible & $19(23.46)$ \\
\hline 3-Perceptible but not noxious & $3(3.7)$ \\
\hline 4-Perceptible and noxious & 0 \\
\hline 5-Perceptible, noxious, and intolerable & 0 \\
\hline
\end{tabular}

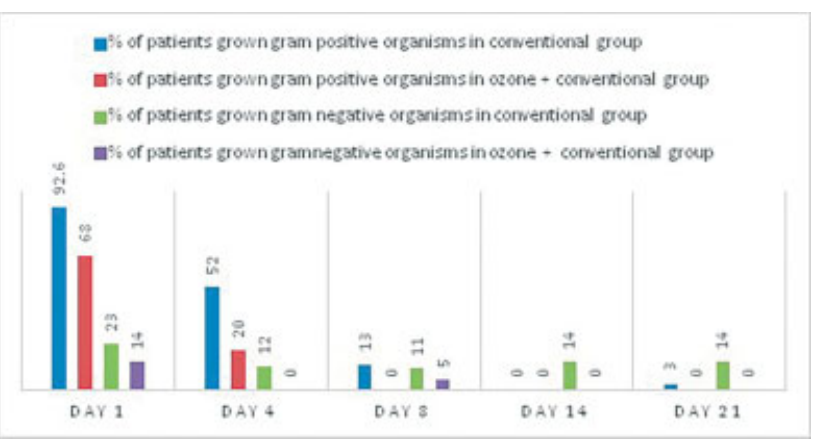

Fig. 9 Comparison of percentages of patients whose ulcers grew gram-positive and gram-negative organisms in both the study groups. over time with $p$-value $<0.05$. Trajectories of the presence of gram-positive organism growth (change in presence of grampositive organism growth over the period of time) for two interventions were significantly different (-Fig. 10).

There is faster rate of microbial negativity with respect to methicillin-susceptible Staphylococcus aureus (MSSA), methicillin-resistant Staphylococcus aureus (MRSA), Escherichia coli, and Pseudomonas in $\mathrm{O}+\mathrm{C}$ group than $\mathrm{C}$ group (-Figs. 11 and 12).

7. Association of hospital stay with $\mathrm{C}$ and $\mathrm{O}+\mathrm{C}$ group: Since the median hospital stay is 9 days in $\mathrm{O}+\mathrm{C}$ group compared with 13 days in $C$ group and $p$-value 0.01 on application of Mann Whitney test, reduction in hospital stay is statistically significant for $\mathrm{O}+\mathrm{C}$ group ( - Table 7)

8. Association of revision (re-debridement and amputations) surgery required in $\mathrm{C}$ and $\mathrm{O}+\mathrm{C}$ group: Patients were followed up for 30 days for outcomes of requirement of revision surgery and mortality. - Table 8 shows that, $42 \%$ patients required revision surgery in $\mathrm{C}$ group while $\mathrm{O}+\mathrm{C}$ group did not require revision surgery with $p$-value 0.01 . This suggests statistically significant reduction in requirement of revision surgery in $\mathrm{O}+\mathrm{C}$ group.

9. Role of ozone gas therapy in the prevention of 30-day mortality: Since the Fischer exact test is showing $p$-value of 0.04 ( - Table 9), this outcome parameter is statistically significant which suggests ozone therapy is associated with reduced mortality.

\section{Discussion}

\section{Rate of Wound Healing}

In double blind randomized control trial (RCT) by Wainstein et al in $2011^{5}$ with $\mathrm{O}+\mathrm{C}$, among the 34 subjects who completed the study per protocol (PP) ( 16 in the $\mathrm{O}+\mathrm{C}$ group, 18 in the placebo group), a significantly higher rate of complete wound closure was observed in the $\mathrm{O}+\mathrm{C}$ group ( 81 vs. $44 \%, p=0.03$ ). Among PP patients with wound size $\leq 5 \mathrm{~cm}^{2}$, the rate of total wound closure was 100 versus $50 \%$ in the sham treatment group $(p=0.006) . p$-Value in this study $(p=0.006)$ is more significant than our study $(p=0.01)$; this might be because of increased sessions of ozone gas therapy.

In Zhang et $\mathrm{al}^{3}$ (RCT) the effective wound healing rate of $\mathrm{O}+\mathrm{C}$ group was significantly higher than that of control group (92 vs. $64 \%, p<0.05$ ). The wound size reduction was significantly more in $\mathrm{O}+\mathrm{C}$ group than in control group $(p<0.001)$. $p$-Value in this study $(p=0.001)$ is more significant than our study $(p=0.01)$ and again this might be because of increased sessions of ozone gas therapy.

Number of sessions ozone to be given and rate of wound healing might be related as seen in Wainstein et al and Zhang et al but large scale RCT is needed to prove this hypothesis.

Ozone is capable of reacting to wide range of organic and inorganic biological substances to cause oxidation. Some of these substrates are proteins, amino acids, and unsaturated fatty acids, which form part of the lipoprotein complexes of 

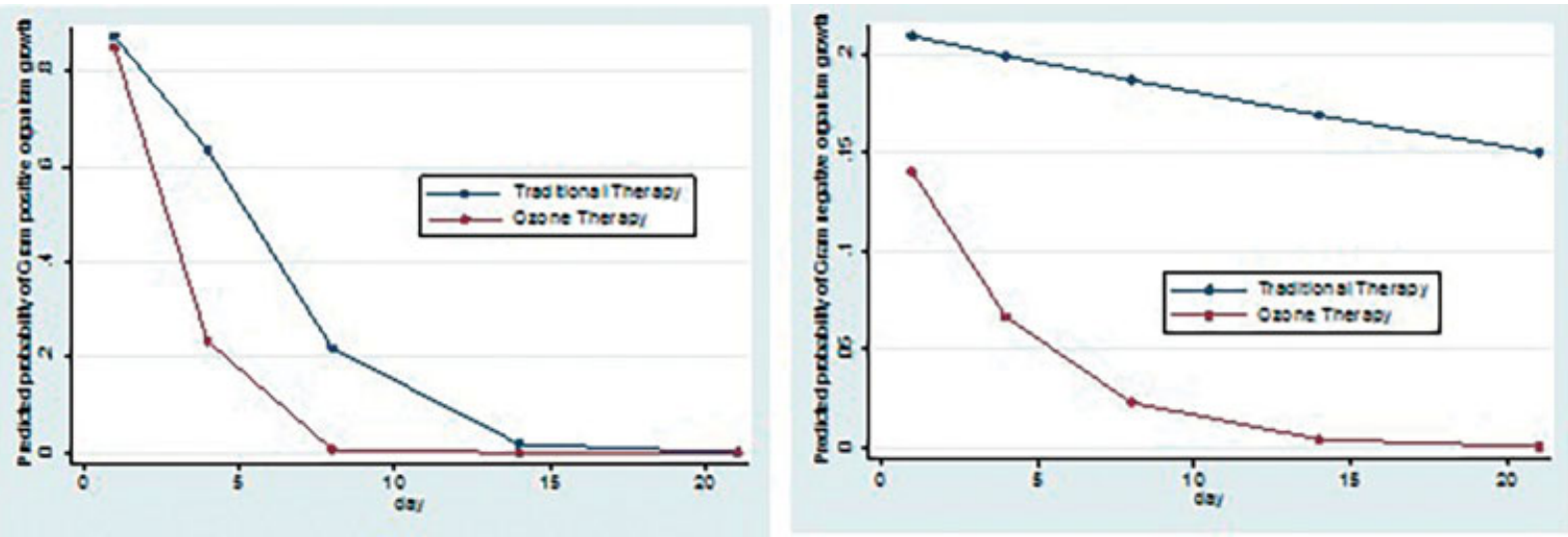

Fig. 10 Predicted probability of gram-positive and gram-negative microorganisms over 21 days in both the study group.

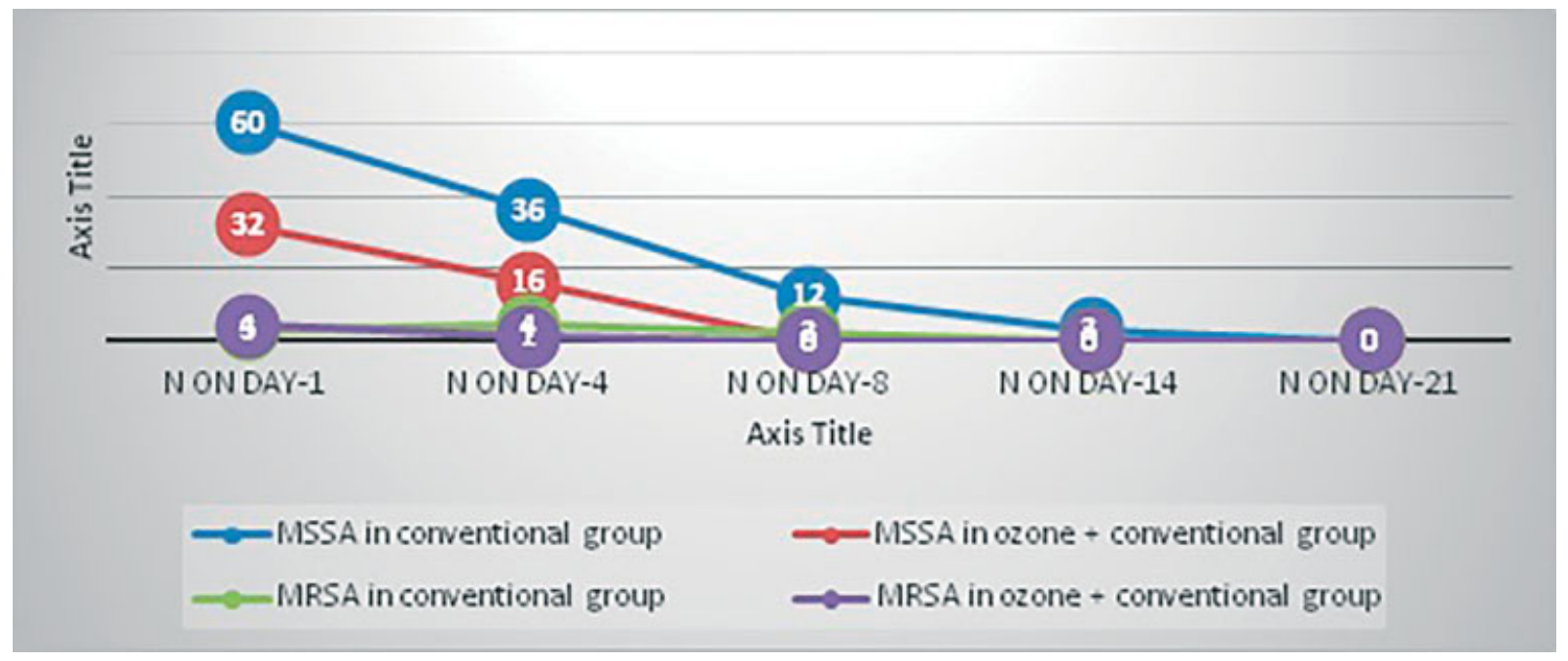

Fig. 11 Trend of MSSA and MRSA in C and O + C group over 21 days. MRSA, methicillin-resistant Staphylococcus aureus; MSSA, methicillinsusceptible Staphylococcus aureus.

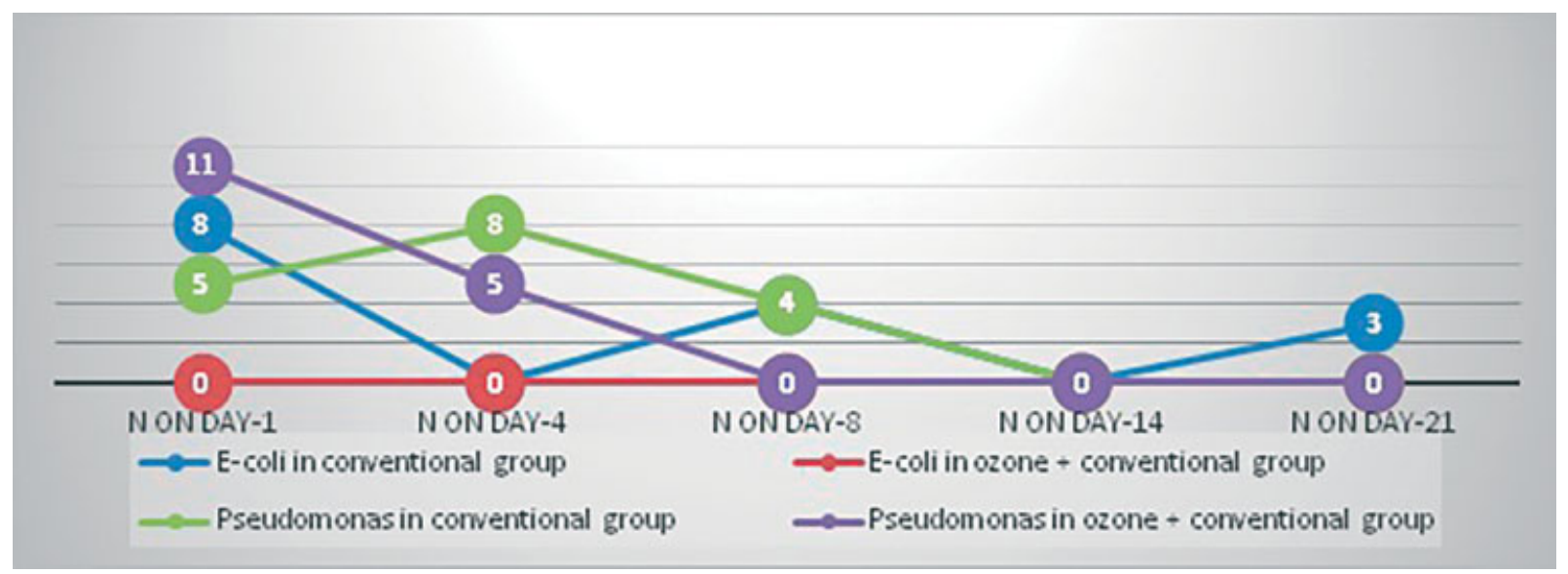

Fig. 12 Trend of E. coli and Pseudomonas in $\mathrm{C}$ and $\mathrm{O}+\mathrm{C}$ group over 21 days.

Table 7 Comparison of hospital stay in two study groups

\begin{tabular}{|l|l|l|l|}
\hline & $\mathbf{C}(\boldsymbol{n}=\mathbf{8 1})$ & $\mathbf{O}+\mathbf{C}(\boldsymbol{n}=\mathbf{8 1})$ & Mann-Whitney U test \\
\hline Hospital stay, median (IQR) & $13(11,16)$ & $9(8,9)$ & $\begin{array}{l}z \text {-Value }=8.16 ; \\
p \text {-Value }=0.01\end{array}$ \\
\hline
\end{tabular}


Table 8 Comparison of revision (re-debridement and amputations) surgery required in two study groups

\begin{tabular}{|l|l|l|l|l|}
\hline & & $\begin{array}{l}\text { C } \\
(\boldsymbol{n}=\mathbf{8 1}),(\%)\end{array}$ & Ozone $+\mathbf{C}(\boldsymbol{n}=\mathbf{8 1}),(\%)$ & Chi-square test \\
\hline Revision surgery within 30 d & No & $47(58.0)$ & $81(100.0)$ & $\begin{array}{l}\text { Chi-square value: } 43.03 ; \\
\text { p-Value: } 0.01 ;\end{array}$ \\
\cline { 2 - 5 } & Yes & $34(42.0)$ & $0(0.0)$ & \\
\hline
\end{tabular}

Table 9 Comparison of mortality within $30 \mathrm{~d}$ post-surgery

\begin{tabular}{|l|l|l|l|l|}
\hline & & $\begin{array}{l}\mathrm{C} \\
(\boldsymbol{n}=\mathbf{8 1}),(\%)\end{array}$ & Ozone $+\mathbf{C}(\boldsymbol{n}=\mathbf{8 1}),(\%)$ & Chi-square test \\
\hline \multirow{2}{*}{ Outcome } & Alive & $77(95.1)$ & $81(100.0)$ & $\begin{array}{l}\text { Chi-square value: } 4.1 ; \\
p \text {-Value by Fischer exact test: } 0.04 ;\end{array}$ \\
\cline { 2 - 4 } & Death & $4(4.9)$ & $0(0.0)$ & \\
\hline
\end{tabular}

plasma and of the double layers of the cellular membranes. Ozone reacts with membrane phospholipid bilayer to form some elements like ozonides, aldehydes, peroxides, and hydrogen peroxide $\left(\mathrm{H}_{2} \mathrm{O}_{2}\right)$. They interact with cellular DNA and cysteine residue and release second messengers, they activate enzymes, such as chemical and immune-response mediators in controlled manner to bring about therapeutic effect of ozone on healing. ${ }^{6}$ Some of the other mechanisms of ozone promoting healing of ulcer are activation of aerobic processes by stimulation of Krebs cycle, broad spectrum antimicrobial property, antioxidant action, stimulation of growth factors, expression of adaptive inflammatory response, induction of synthesis of interleukins and leukotrienes, secretion of vasodilators like nitric oxide, and enhancement of immune system. ${ }^{7-10}$

The immunological action of ozone on the blood is directed, fundamentally, to the monocytes and T lymphocytes, which once induced, releases small quantities of practically all the cytokines in an endogenous and controlled manner. This regulation is affected by the ozone which acts as an enhancer of the immunological system by activating neutrophils and stimulating synthesis of some of these cytokines. ${ }^{11,12}$

Certain transcription factors like NFK- $\beta$ intervene in the regulation which favor the transcription and transduction processes at DNA level and lead to the upregulation or suppression of synthesis of either pro-inflammatory or anti-inflammatory cytokines (-Fig. 4). ${ }^{13}$

\section{Character of Ulcer Exudate}

The character of ulcer exudate changes from purulent to seropurulent after debridement and as ulcer heals it converts to serosanguinous then finally to serous. This change is faster in $\mathrm{O}+\mathrm{C}$ group compared with $\mathrm{C}$ group $(p<0.05$, generalized estimation equation). Hence character of ulcer exudate is one of the good assessment parameter for healing of ulcers. No studies are present in the current scenario to study this parameter.

\section{Rate of Formation of Healing Granulation Tissue}

Healing granulation tissue indicates recovery of ulcer from infection. At any given time point, in our study, healing granulation tissue score is estimated to be $20 \%$ more for patients receiving $\mathrm{O}+\mathrm{C}$ therapy compared with patient receiving $C$ therapy. This difference was statistically significant. Hence ozone might help in induction of faster rate of formation of healing granulation tissue. No studies present in current scenario to study this parameter.

\section{Rate of Formation of Healing Wound Edges}

Like healing granulation tissue, healing wound edges along with disappearance of signs of inflammation in surrounding skin area indicate early recovery of the ulcer. Presence of fibrotic, punched out, rolled out, or undermined ulcer edges indicate chronicity of ulcer. These are signs of nonhealing of ulcer. Slopping ulcer edges are considered healthy.

On day 21 , healing wound edges score was estimated to be $27 \%$ more for patients receiving $\mathrm{O}+\mathrm{C}$ therapy $(p<0.05$ by generalized estimation equation) compared with patient receiving $C$ treatment. This difference was statistically significant. And disappearance of signs of inflammation in surrounding skin was much faster in $\mathrm{O}+\mathrm{C}$ group. Hence ozone might help in disappearance of signs of inflammation and faster induction of healing of wound edges. This might be because of immune modulation function of ozone.

\section{Adverse Effects of Ozone}

Ozone is not a drug and as such it does not cause side effects, does not cause allergic reactions, and in general has no reported interactions with other drugs. Ozone in general is well tolerated by the patients. But in excessive doses few patients feel sensation of heaviness. It is for short duration and is resolved spontaneously. The use of plastic bags permeable to ozone leads to discomfort such as headaches. If the proper material is not used, the ozone reacts with the plastic material and introduces toxic compounds in the blood which are responsible for the adverse effects described. ${ }^{14}$ In summary, the side effects are related to high doses of ozone, inappropriate use of materials, and thus are easily preventable.

\section{Rate of Microbial Negativity}

Early microbial negativity indicates potency and efficacy of the drug or intervention. Our study shows faster rate of microbial negativity, i.e., $100 \%$ by day 8 for gram-positive organisms and that by day 14 for gram-negative organisms in $\mathrm{O}+\mathrm{C}$ group. 
While in C group microbial negativity was achieved on day 14 for gram-positive organisms and it was not achieved at all for gram-negative organisms ( $86 \%$ reduction).

Ozone is specifically effective against MSSA and MRSA (Gulmen et al and Song et al) ${ }^{15,16}$ amongst gram-positive organisms while E. coli and Pseudomonas amongst gramnegative organisms. In a study by Fontes et al ${ }^{17}$ MRSA was cleared on day 4 in $\mathrm{O}+\mathrm{C}$ group while it persisted till day 8 in $\mathrm{C}$ group. Pseudomonas was cleared on day 8 in $\mathrm{O}+\mathrm{C}$ group while it required 14 days to clear in $C$ group.

In Song et al, ${ }^{16}$ clinical efficacy and safety of topical ozone were evaluated in two cases with skin MRSA infection. The killing rates of ozonated oil for S. aureus and MRSA were greater when compared with the control oil group. Almost $100 \%$ of $S$. aureus were eliminated by ozonated oil in 5 minutes and MRSA in 15 minutes. In addition, $100 \%$ S. aureus and $100 \%$ MRSA were eliminated by ozonated water in 1 minute.

Gulmen et $\mathrm{al}^{15}$ found that both the vancomycin and the ozone treatments caused significant reduction of bacterial counts in quantitative bacterial cultures. Histologic examination of tissue samples revealed significant reduction in severity of mediastinitis-related inflammation in vancomycin and vancomycin ozone groups compared with untreated contaminated group.

Fontes et al, ${ }^{17}$ says that when selected ozone dose was applied to the following eight strains: Escherichia coli, oxacillin-resistant Staphylococcus aureus, oxacillin-susceptible $S$. aureus, vancomycin-resistant Enterococcus faecalis, extended-spectrum $\beta$-lactamase-producing Klebsiella pneumoniae, carbapenem-resistant Acinetobacter baumannii, A. baumannii susceptible only to carbapenems, and Pseudomonas aeruginosa susceptible to imipenem and meropenem. All isolates were completely inhibited by the ozone-oxygen mixture while growth occurred in the other 2 control groups.

\section{Miscellaneous Effects of Ozone}

Enas Mohammed Ali ${ }^{18}$ studied the antifungal action of ozone gas therapy for DFU.

Spore viability of $C$. albicans was reduced by over $99.5 \%$ at 3 ppm ozone concentration after 180 minutes' exposure time. Prevention of mycelial growth in A. flavus was detected with $100 \%$ inhibition efficacy at 3 ppm ozone after 210 minutes. The study also determined the efficiency of ozonation in degrading mycotoxins produced by most dominant mycotoxigenic fungal species. The production of aflatoxins and trichothecene toxins was greatly inhibited at $3 \mathrm{ppm}$ ozone after 180 minutes.

Wells et al ${ }^{19}$ studied the antiviral effect of ozone on HIV-1 virus in vitro. Ozone was found to inactivate HIV-1 virions in a dose-dependent manner. Ozone treatment offers promise as a means to inactivate human retroviruses in human body fluids and blood product preparations.

\section{Actions of Ozone 20 $^{20}$}

- It has high oxidizing capacity and acts on microbial wall, which acts on bacteria, viruses, and fungi; hence it has broad spectrum activity.
- It is effective even on highly resistant microbial flora.

- It improves the delivery of oxygen to the tissues.

- It improves the red blood cell metabolism, making the metabolism of glucose more efficient.

- It improves the metabolism of the fatty acids for the activation of antioxidant enzymes in charge of eliminating peroxides and free radicals.

- The principal metabolic effects attributed to ozone are:

1. Increment of the use of glucose at the cellular level.

2. It improves the protein metabolism.

3. Direct effects on the unsaturated lipids, it oxidizes them and induces at the same time the repair mechanisms.

- Ozone has a dual action mechanism: analgesic and antiinflammatory. These effects seem to be due to its way of acting on diverse targets:

1. Decrease the production of mediators of the inflammation.

2. The oxidation (inactivation) of metabolic mediators of pain.

3. It clearly improves local blood microcirculation, with an improvement in the oxygen delivery to the tissues, essential for the regeneration of anatomical structures; the elimination of toxins and in general the resolution of the physiological disturbance that generated the pain.

\section{Reduction in Hospital Stay}

Because of faster rate of ulcer healing and early microbial negativity, hospital stay of patients has significantly reduced in our study in $\mathrm{O}+\mathrm{C}$ group. Hence ozone gas indirectly helps to decrease the overall cost expenditure for management of DFU. Rosul and Patskan studied RCT for DFU; there was significantly faster rate of wound healing, lipid peroxidation, reduction in hospital stay, greater antioxidant protection, and yielded significant decrease in microbial colonization of wounds. ${ }^{21}$

\section{Requirement of Revision Surgeries (Re-debridement/Amputation)}

Because of effective antimicrobial, antioxidant, and immune modulation property of ozone there was faster rate of microbial negativity and ulcer healing and decreased requirement of revision surgeries. Forty-two percent of patients required revision surgery in $\mathrm{C}$ group while $\mathrm{O}+\mathrm{C}$ group did not require revision surgery with $p$-value 0.01 by Chi-square test. This suggests statistically significant reduction in requirement of revision surgery in $\mathrm{O}+\mathrm{C}$ group. Similar study by Izadi et $\mathrm{al}^{22}$ found similar results, i.e., there was decrease in chances of wound re-infections and amputations in $\mathrm{O}+\mathrm{C}$ group compared with control group.

\section{Role in Mortality Prevention}

There were no deaths observed in $\mathrm{O}+\mathrm{C}$ group while percentage mortality in C group was $4.9 \%$ on 1 month follow-up. $p$-Value by Fischer exact test was found to be 0.04 which is statistically significant. Three deaths were seen in patients who required revision surgery and one of them had MRSA infection. These deaths were due to septic complications of 
diabetic foot and not due to other co-morbid conditions. As we discussed above, because of effective antimicrobial and immune modulation property of ozone there was faster rate of microbial negativity, ulcer healing, and decreased requirement of revision surgeries. Hence ozone has a role in prevention of both DFU morbidity and 30 day mortality.

\section{Limitations of This Study}

1. Our study was nonrandomized.

2. Population was heterogenous with having different inherent wound healing capacity due to different age, gender, and co-morbid conditions leading to multiple confounding factors.

3. Smaller duration of follow-up (21 days) due to social or technical issues of the hospital.

\section{Strengths of This Study}

1. Our study is prospective.

2. Accurate measurement of ulcer surface area and maximum diameter (with tracing paper with minimum surface area of $1 \mathrm{~mm}^{2}$ ).

3. Since study population is heterogenous, results are applicable to wider range of population.

4. Various new parameters of DFU have been studied which have not studied previously, i.e., character of exudate, presence of ulcer odor, rate of formation of healing granulation tissue, and rate of formation of healing wound edges after application of ozone gas therapy.

\section{Conclusion}

1. This study proves efficacy of topical ozone gas therapy and provides clinical evidence to support use of ozone. We recommend it for faster healing of DFU.

2. This study confirms antimicrobial potency of ozone gas therapy.

3. This study shows that dose of $40 \mu \mathrm{g} / \mathrm{mL}$ (range $=30-50$ $\mu \mathrm{g} / \mathrm{mL}$ ) of topical ozone gas therapy is optimal for DFU. And ozone gas is well tolerated by patients at this concentration without any significant adverse effects.

4. We recommend using ozone gas therapy for reduction in hospital stay and reduction in requirement of revision (redebridement and amputations) surgeries. It also has a role in reduction of 30 days mortality.

5. Thus, ozone therapy is very effective, cheap, simple, well tolerated, and easily reproducible but underutilized tool. It does not require huge infrastructure or complex equipment. Also, no recurring cost of consumables is involved making it a very suitable tool to promote wound healing in DFUs in resource-constraint regions.

\section{Funding}

None.

\section{Conflict of Interest}

None declared.

\section{References}

1 Joshi SR. Diabetes care in India. Ann Glob Health 2015;81(06): 830-838

2 Liu J, Zhang P, Tian J, et al. Ozone therapy for treating foot ulcers in people with diabetes. Cochrane Database Syst Rev 2015;(10): CD008474

3 Zhang J, Guan M, Xie C, Luo X, Zhang Q Xue Y. Increased growth factors play a role in wound healing promoted by noninvasive oxygen-ozone therapy in diabetic patients with foot ulcers. Oxid Med Cell Longev 2014;2014:273475

4 Bocci VA. Scientific and medical aspects of ozone therapy. State of the art. Arch Med Res 2006;37(04):425-435

5 Wainstein J, Feldbrin Z, Boaz M, Harman-Boehm I. Efficacy of ozone-oxygen therapy for the treatment of diabetic foot ulcers. Diabetes Technol Ther 2011;13(12):1255-1260

6 Martínez-Sánchez G, Schwartz A, Di Donna V. Potential cytoprotective activity of ozone therapy in SARS-CoV-2/COVID-19. Antioxidants (Basel) 2020;09(05):389

7 German I, de Castro R, Andreo JC, et al. Major biological effects of ozone therapy. Accessed December 10, 2019 at: https://www. researchgate.net/figure/Major-biological-effects-of-ozone-therapy_fig1_262662651

8 Bocci V. Ozone: A New Medical Drug. Dordrecht: Springer Netherlands; 2005:1-295

9 Seidler V, Linetskiy I, Hubálková H, Stanková H, Smucler R, Mazánek J. Ozone and its usage in general medicine and dentistry. A review article. Prague Med Rep 2008;109(01):5-13

10 Medina A, Fry M. Ozonoterapia en odontología: Tratamiento alternativo en Periodoncia. JPAPO 2019;03(01):57-64

11 Bocci V, Paulesu L. Studies on the biological effects of ozone 1. Induction of interferon gamma on human leucocytes. Haematologica 1990;75(06):510-515

12 Bocci V, Luzzi E, Corradeschi F, Paulesu L. Studies on the biological effects of ozone: 5. Evaluation of immunological parameters and tolerability in normal volunteers receiving ambulatory autohaemotherapy. Biotherapy1993-19947(02):83-90

13 Bocci V, Valacchi G, Corradeschi F, Fanetti G. Studies on the biological effects of ozone: 8. Effects on the total antioxidant status and on interleukin-8 production. Mediators Inflamm 1998; 7(05):313-317

14 Borrelli E. Mechanism of action of oxygen ozone therapy in the treatment of disc herniation and low back pain. Acta Neurochir Suppl (Wien) 2011;108(108):123-125

15 Gulmen S, Kurtoglu T, Meteoglu I, Kaya S, Okutan H. Ozone therapy as an adjunct to vancomycin enhances bacterial elimination in methicillin resistant Staphylococcus aureus mediastinitis. J Surg Res 2013;185(01):64-69

16 Song M, Zeng Q, Xiang Y, et al. The antibacterial effect of topical ozone on the treatment of MRSA skin infection. Mol Med Rep 2018;17(02):2449-2455

17 Fontes B, Cattani Heimbecker AM, de Souza Brito G, et al. Effect of low-dose gaseous ozone on pathogenic bacteria. BMC Infect Dis 2012;12:358

18 Ali E. Ozone application for preventing fungal infection. Diabetalogia Croat 2013;42(01):3-9

19 Wells KH, Latino J, Gavalchin J, Poiesz BJ. Inactivation of human immunodeficiency virus type 1 by ozone in vitro. Blood 1991;78 (07):1882-1890

20 Schwartz A, Director MD, Martínez-Sánchez G. Secretary of the International Scientific Committee of Ozone Therapy (ISCO3). Rev Española Ozonoterapia 2012;2(01):199-232

21 Rosul MV, Patskan BM. Ozone therapy effectiveness in patients with ulcerous lesions due to diabetes mellitus. Wiad Lek 2016; 69(01):7-9

22 Izadi M, Kheirjou R, Mohammadpour R, et al. Efficacy of comprehensive ozone therapy in diabetic foot ulcer healing. Diabetes Metab Syndr 2019;13(01):822-825 